OPEN ACCESS

Edited by:

Hui Cai,

Emory University, United States

Reviewed by:

Eleanor DeLand Lederer, University of Texas Southwestern

Medical Center, United States

Aihua Zhang,

Nanjing Children's Hospital, China

${ }^{*}$ Correspondence:

Tianxin Yang

Tianxin.Yang@hsc.utah.edu

Specialty section

This article was submitted to

Renal and Epithelial Physiology,

a section of the journal

Frontiers in Physiology

Received: 28 September 2021

Accepted: 14 January 2022

Published: 11 February 2022

Citation:

Lu A, Pu M, Mo S, Su J, Hu J,

Li C, Wang W and Yang T (2022)

(Pro)renin Receptor Regulates Phosphate Homeostasis in Rats via

Releasing Fibroblast Growth

Factor-23. Front. Physiol. 13:784521.

doi: $10.3389 /$ fphys.2022.784521

\section{(Pro)renin Receptor Regulates Phosphate Homeostasis in Rats via Releasing Fibroblast Growth Factor-23}

\author{
Aihua $\mathrm{Lu}^{1}$, Min $\mathrm{Pu}^{1}$, Shiqi Mo ${ }^{1}$, Jiahui Su${ }^{1}$, Jiajia $\mathrm{Hu}^{1}$, Chunling $\mathrm{Li}^{1}$, Weidong Wang ${ }^{1}$ and \\ Tianxin Yang ${ }^{2 *}$
}

${ }^{1}$ Institute of Hypertension, Zhongshan School of Medicine, Sun Yat-sen University, Guangzhou, China, ${ }^{2}$ Department of Internal Medicine, University of Utah and Veterans Affairs Medical Center, Salt Lake City, UT, United States

Phosphate $(\mathrm{Pi})$ is one of the basic necessities required for sustenance of life and its metabolism largely relies on excretory function of the kidney, a process chiefly under the endocrine control of bone-derived fibroblast growth factor 23 (FGF23). However, knowledge gap exists in understanding the regulatory loop responsible for eliciting phophaturic response to $\mathrm{Pi}$ treatment. Here, we reported a novel role of (pro)renin receptor (PRR) in mediating phosphaturic response to Pi treatment via upregulation of FGF23 production. Male Sprague-Dawley rats were pretreated for 5 days via osmotic pump-driven infusion of a PRR antagonist $\mathrm{PRO} 20$ or vehicle, and then treated with high $\mathrm{Pi}(\mathrm{HP})$ solution as drinking fluid for the last $24 \mathrm{~h}$. PRO20 reduced HP-induced Pi excretion by $42 \%$, accompanied by blunted upregulation of circulating FGF23 and parathyroid hormone (PTH) and downregulation of renal Na/Pi-lla expression. In cultured osteoblast cells, exposure to HP induced a 1.56-fold increase in FGF23 expression, which was blunted by PRO20 or siRNA against PRR. Together, these results suggest that activation of PRR promotes phosphaturic response through stimulation of FGF23 production and subsequent downregulation of renal $\mathrm{Na} / \mathrm{Pi}$-lla expression.

Keywords: (pro)renin receptor, fibroblast growth factor 23, phosphate homeostasis, $\mathrm{Na}^{+}$-dependent $\mathrm{Pi}$ transporter, parathyroid hormone

\section{INTRODUCTION}

Phosphate $(\mathrm{Pi})$ is an essential nutrient and component of the human body. Adequate phosphate balance is essential for the maintenance of fundamental cellular functions of the mammalian system, ranging from energy metabolism to mineral ion metabolism (Gaasbeek and Meinders, 2005). The kidney plays a pivotal role in maintenance of Pi homeostasis by adjustment of reabsorption and excretion (Shimada et al., 2004a; Urakawa et al., 2006). In the kidney, most of the filtered Pi is reabsorbed across the proximal tubule cells (Katai et al., 1999 Giral et al., 2009). Evidence from physiological studies suggests that $\mathrm{Na}^{+}$-dependent $\mathrm{Pi}$ transporters in the brushborder membrane (BBM) of proximal tubular cells mediate the rate-limiting step in the overall Pi-reabsorptive process (Murer et al., 2000, 2003). An alteration of proximal tubular reabsorption 
of Pi in kidney was thought to depend on the abundance of NaPilla $(\mathrm{Npt} 2 \mathrm{a})$ or NaPi-llc (Npt2c) proteins residing in the BBM (Biber and Murer, 1994; Busch et al., 1994; Shirazi-Beechey et al., 1996). $\mathrm{Na}^{+}$- Pi cotransporter knock out mouse demonstrated that $\mathrm{NaPi}$-lla was responsible for approximately $70 \%$ of $\mathrm{BBM} \mathrm{Na} / \mathrm{Pi}$ cotransport activity (Beck et al., 1998; Murer et al., 2004).

Renal handling of $\mathrm{Pi}$ is tightly regulated by endocrine hormones, particularly fibroblast growth factor 23 (FGF23), vitamin $\mathrm{D}_{3}$, and PTH (Pfister et al., 1998; Shimada et al., 2004a; Liu et al., 2006; Farrow et al., 2009; Gattineni et al., 2009; Guo et al., 2013). Among these, FGF23 is a bone-derived hormone secreted by osteoblasts and osteocytes in response to increased Pi concentration as well as vitamin D (Saito et al., 2005; Antoniucci et al., 2006; Perwad et al., 2007). FGF23 acts on the distal convoluted tubule that may trigger a cascade that reduces proximal tubular Pi reabsorption (Farrow et al., 2009). Studies in animal models have shown that increased serum concentrations of FGF23 lead to renal Pi wasting through downregulation of Npt2a and Npt2c in the proximal tubule (PT) apical membrane (Larsson et al., 2004; Shimada et al., 2004b).

(Pro)renin receptor (PRR) is a member of the reninangiotensin system (RAS) (Nguyen et al., 2002) and generally thought to serve as a specific receptor for both prorenin and renin. PRR is composed of a large $\mathrm{N}$-terminal extracellular domain, a single transmembrane domain, and a short cytoplasmic domain (Burckle and Bader, 2006). The full length PRR (fPRR) is cleaved by site-1 protease (S1P) to generate $\mathrm{N}$-terminal soluble PRR (sPRR) and the C-terminal membranebound M8-9 fragment (Nakagawa et al., 2017). Increasing evidence has demonstrated that PRR-mediated activation of the intrarenal RAS plays an essential role in renal handling of $\mathrm{Na}^{+}$and water balance (Gonzalez and Prieto, 2015; Lu et al., 2016a,b; Quadri and Siragy, 2016; Peng et al., 2017; Prieto et al., 2017). Activation PRR triggers multiple signaling transduction pathways such as $\beta$-catenin signaling and thus can act in a RAS-independent manner (Kouchi et al., 2017; Li et al., 2017; Gao et al., 2020). So far, there is no prior research to address a potential role of $\mathrm{PRR}$ in regulation of $\mathrm{Pi}$ homeostasis. The overall goal of the present study was to test the role of PRR in phosphaturic response to HP treatment and further to address the underlying mechanism.

\section{MATERIALS AND METHODS}

\section{Animals}

Male Sprague-Dawley rats (220-270 g) were purchased from the Medical Experimental Animal Center at Sun Yat-sen University. All animal protocols were conformed to the Experimental Animal Management Regulations of Sun Yat-sen University. Rats were acclimated in metabolic cages for 3 days prior to the start of the study. Rats were randomly divided into three experimental groups ( $N=5$ per group): (1) control group, (2) HP group, or (3) $\mathrm{HP}+\mathrm{PRO} 20$ group. Animals in $\mathrm{HP}$ and $\mathrm{HP}+\mathrm{PRO} 20$ groups drank high phosphate fluid $(5 \times$ phosphate buffered saline, $\mathrm{pH}$ $7.4,[\mathrm{Pi}]=50 \mathrm{mM}$ ) for $24 \mathrm{~h}$ (Ide et al., 2016) and the control group drank tap water. Five days prior to HP treatment, osmotic minipump (2001, Alzet, United States) was implanted to deliver vehicle or PRO20 at $700 \mu \mathrm{g} / \mathrm{kg} / \mathrm{d}$ as previously described (Wang et al., 2016, 2020). Twenty four-hour urine was collected using metabolic cages.

\section{Plasma and Urine Parameters}

Plasma and urine creatinine was determined by the QuantiChrom $^{\text {TM }}$ Creatinine Assay Kit (DICT-500, BioAssay Syatems, United States). Plasma and urine sodium, potassium and chlorine levels were determined by the Sodium, Potassium and Chlorine Assay Kit, respectively (Nanjing Jiancheng Bioengineering Institute, China). Plasma and urine phosphorus and calcium levels were determined by the Micro Blood Phosphorus and Calcium Concentration Assay Kit, respectively (Solarbio life sciences, China). Plasma and urine soluble PRR (sPRR) levels were determined by the ELISA kit (27782, IBL, Japan). Plasma FGF23, PTH and $1,25(\mathrm{OH})_{2} \mathrm{D}_{3}$ concentrations were assayed using the ELISA kits (Cloud-Clone Corp., China). All of these ELISA assays were performed according to the manufacturer's protocols.

\section{Isolation of Renal Brush-Border Membranes}

Renal BBMs were isolated by double magnesium chloride $\left(\mathrm{MgCl}_{2}\right)$ precipitation as previously described (Gattineni et al., 2009) with minor modifications. After removal of the renal capsule, the renal cortex was isolated and homogenized in $2 \mathrm{ml}$ of cold $2 \times$ homogenization buffer ( $12 \mathrm{mM}$ Tris $\mathrm{pH} 7.4$, $300 \mathrm{mM}$ mannitol, $5 \mathrm{mM}$ EGTA). $\mathrm{MgCl}_{2}$ was added to a final concentration of $12 \mathrm{mM}$ and samples were incubated on ice for 15 min with occasional mixing. Then the aggregated membranes were removed by 15 -min centrifugation at $3,000 \mathrm{~g}$ and $4^{\circ} \mathrm{C}$, and the supernatant was then centrifuged for $30 \mathrm{~min}$ at 40,000 $g$ and $4^{\circ} \mathrm{C}$. The pellet was resuspended in $1 \mathrm{ml}$ of $1 \times$ cold homogenization buffer supplemented with $12 \mathrm{mM} \mathrm{MgCl}_{2}$. After a second incubation and 15 -min centrifugation at $3,000 \mathrm{~g}$ and $4^{\circ} \mathrm{C}$ and the supernatant was recovered and centrifuged at $40,000 \mathrm{~g}, 4^{\circ} \mathrm{C}$, for $30 \mathrm{~min}$. The BBM pellets were resuspended in RIPA buffer. All solutions were supplemented with protease inhibitors (1 mM PMSF).

\section{Immunoblotting}

Protein samples were fractionated on SDS-PAGE (30 $\mu \mathrm{g} /$ well) and transferred to a nitrocellulose membrane (Millipore). Immunoblots were incubated overnight at $4^{\circ} \mathrm{C}$ with primary antibodies including anti-ACE (1:1,000, GTX100923, GeneTex, United States), anti-AGT (1:1,000, GTX103824, GeneTex, United States), anti-renin (1:1,000, sc-133145, Santa, United States), anti-PRR (1:1,000, HPA003156, Sigma, United States), anti-Npt2a (1:1,000, A6742, Abclonal, China), anti-Npt2c (1:1,000, ab155986, Abcam, United Kingdom) or anti- $\beta$-actin (1:10,000, A1978, Sigma, United States) antibody in $1.5 \%(\mathrm{w} / \mathrm{v})$ bovine serum albumin (BSA, Sigma, United States) in a TBS-T buffer [150 mM NaCl, $10 \mathrm{mM}$ Tris $(\mathrm{pH} 7.4 / \mathrm{HCl}), 0.2 \%$ (v/v) Tween-20]. After washing, membranes were incubated with horseradish peroxidase-conjugated secondary antibodies 
(1:3,000, Thermo Fisher Scientific ${ }^{\mathrm{TM}}$ Pierce $\left.^{\mathrm{TM}}\right)$. Specific signal was visualized by ECL kit (Thermo Fisher Scientific ${ }^{\text {TM }}$ Pierce $^{\mathrm{TM}}$ ). The protein bands were detected using Amersham Imager 600 and quantified by Image Pro Plus version 6.0 software (Molecular Dynamics).

\section{Quantitative Reverse Transcriptase PCR}

Total RNA was extracted using Trizol (TRIzol, Invitrogen) following manufacturer's instructions. RNA concentrations were quantified at $260 \mathrm{~nm}$, and purity and integrity were determined using NanoDrop 2000. Reverse transcription was performed using iScript ${ }^{\mathrm{TM}}$ cDNA Synthesis Kit (Bio-Rad, United States). The mRNA expression was measured by quantitative RT-PCR using SYBR ${ }^{\circledR}$ Premix Ex Taq ${ }^{\text {TM }}$ II (Tli RNaseH Plus, TaKaRa, China). The following primers were used: ACE: 5'-GAGCCATCCTTCCC-TTTTTC-3' (forward) and $5^{\prime}$-CCACATGTTCCCTAGCAG-GT-3' (reverse), AGT: 5' AGCATCCTCCTTGAACTCCA-3' (forward) and 5' -TGATTTT TGCCCAGGAT- -AGC-3' (reverse), renin: 5'-GATCACCATG AAGGGG-GTCTCTGT-3' (forward) and $5^{\prime}$-GTTCCTGAAG GGATTCTTTTGCAC-3' (reverse), PRR: 5'-CTGGTGGCG-GGTGCTTTAG-3' (forward) and 5'-GCTACGTCTGGGAT-TC GATCT-3' (reverse), Npt2a: 5'-GCCAGCATGACGTTTG
TTGT-3' (forward) and 5'-ATCACACCCAGG-CCAATGAG$3^{\prime}$ (reverse), Npt2c:5'-TGACTGTCCAAGCGT-CTGTC-3 ${ }^{\prime}$ (forward) and 5'-TTCATCCCGATCCCCTGACT-3' (reverse). GAPDH served as an internal control and its primer sequences were: 5'-GTCTTCACTACCA-TGGAGAAGG-3' (forward) and 5'-TCATGGATGACCTT-GGCCAG-3' (reverse).

\section{Immunohistochemistry}

Under anesthesia, kidneys were harvested and fixed with $10 \%$ paraformaldehyde. Paraffin embedded kidney sections were processed for IHC as previously described (Wang et al., 2015). Primary antibody for PRR (1:200, ab40790, Abcam, United Kingdom) was incubated overnight at $4^{\circ} \mathrm{C}$. Sections were washed three times with $0.01 \mathrm{M}$ PBS buffer and secondary antibody horseradish peroxidase (HRP)-conjugated goat anti-rabbit (1:300, Thermo Fisher Scientific) was incubated at room temperature for an hour. The staining procedure was performed using DAB Horseradish Peroxidase Color Development Kit (P0202, Beyotime Biotechnology, China) according to the manufacturer's protocols. Immunohistochemical staining was detected with an Olympus BX 63 microscope $(20 \times$ and 40 $\times$ objective).
A

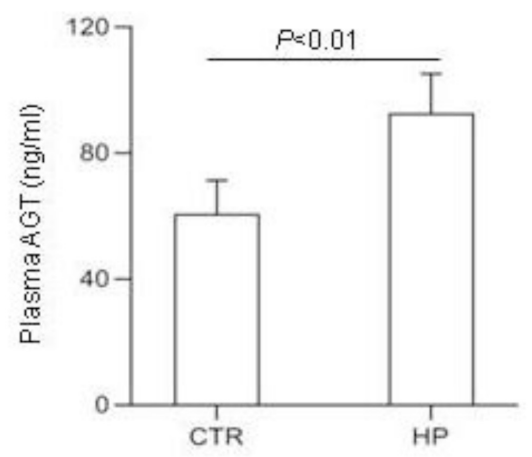

D

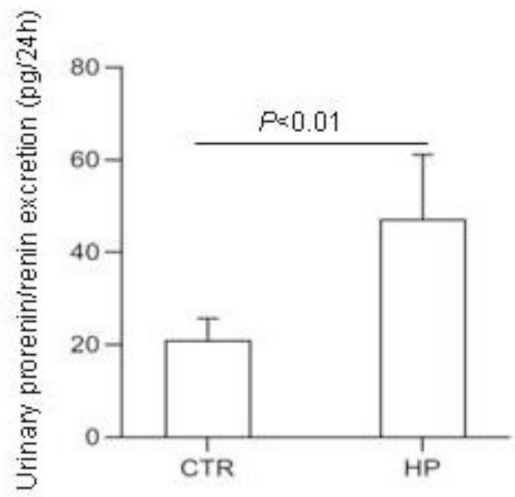

B

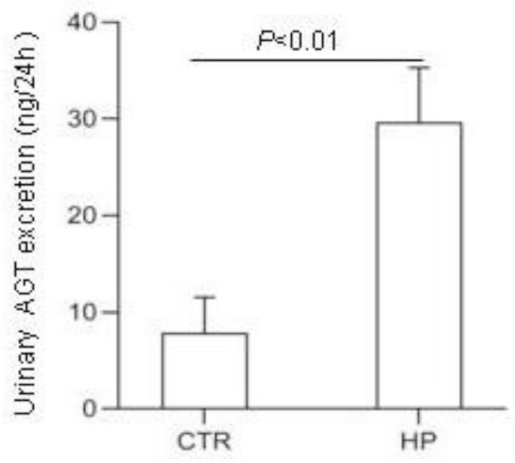

E

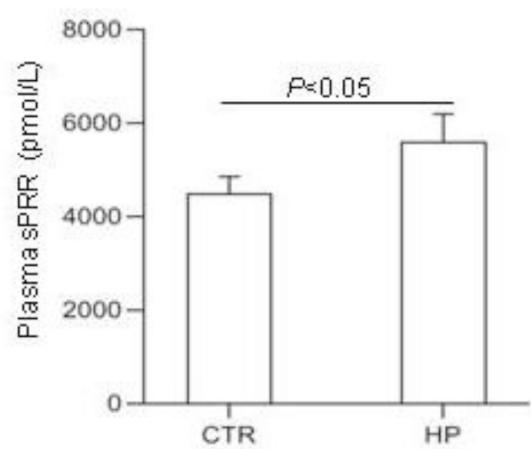

C

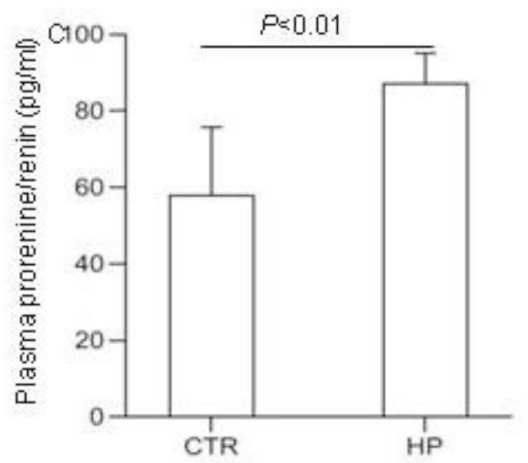

$\mathbf{F}$

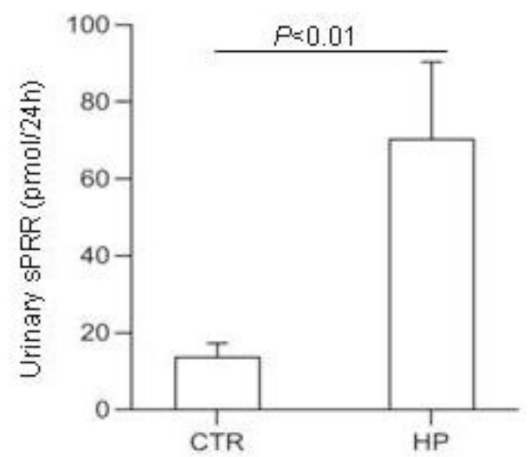

FIGURE 1 | Analysis of the RAS components in rat plasma and urine following HP intake. (A) Plasma angiotensin (AGT) concentration. (B) Urinary AGT excretion. (C) Plasma renin concentration. (D) Urinary renin excretion. (E) Plasma soluble (pro)renin receptor (SPRR) concentration. (F) Urinary sPRR excretion. CTR, control; $\mathrm{HP}$, high Pi intake $N=5$ per group. Data are Mean \pm SEM. 


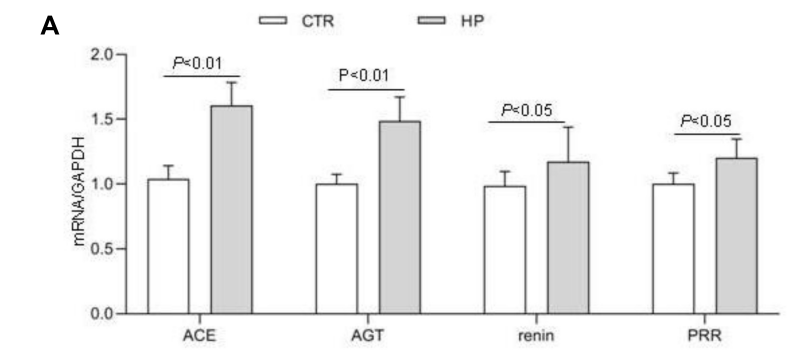

B

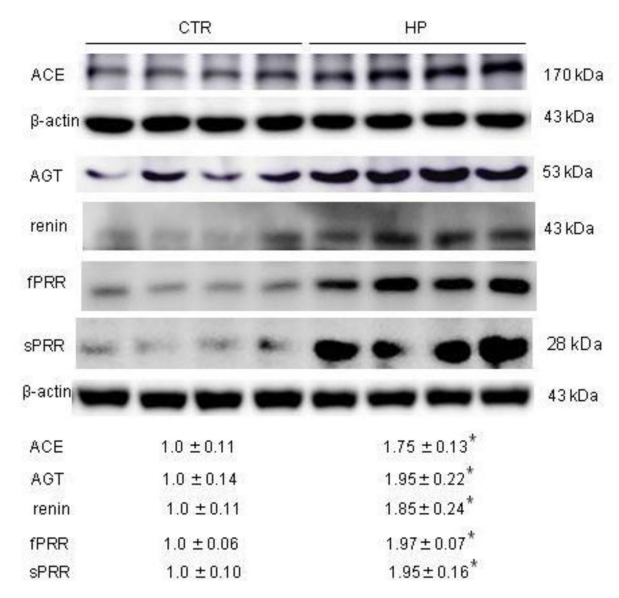

C

$200 \times$

$400 \times$

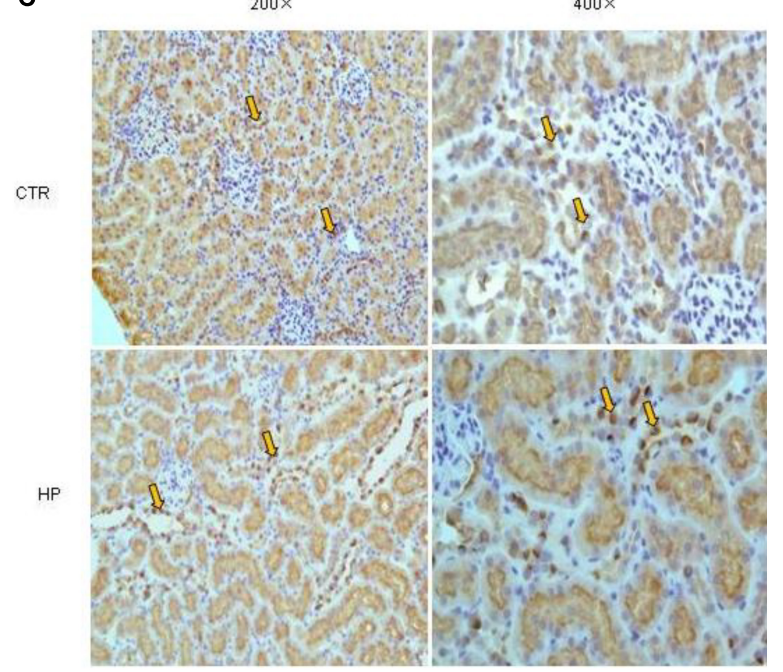

FIGURE 2 | Analysis of the RAS components in rat kidneys following HP intake. (A) qRT-PCR detection of renal transcripts of ACE, AGT, renin, and PRR. GAPDH was used as internal reference. (B) Immunoblotting analysis of renal expression of ACE, AGT, renin, fPRR and sPRR. The values indicate the corresponding densitometry analysis. $\beta$-actin was used as an internal reference. (C) Representative images of PRR immunostaining. Arrows indicate positive staining $(200 \times, 400 \times) . N=5$ per group. Data are Mean \pm SEM. ${ }^{*} p<0.05$ vs. CTR.

\section{Cell Culture}

The MC3T3-E1 cells were obtained from as a gift from Dr. Zhi Tan (Sun Yat-sen University). Cells were cultured in MEMaalpha (Thermo Fisher Scientific) supplemented with $10 \%$ fetal
TABLE 1 | General physiological data in rats.

\begin{tabular}{|c|c|c|c|}
\hline & CTR & HP & $\mathrm{HP}+\mathrm{PRO} 20$ \\
\hline Fluid intake (ml/24 h) & $25.42 \pm 0.63$ & $12.61 \pm 0.38^{\star \star}$ & $12.21 \pm 0.58^{\star \star}$ \\
\hline Urine volumes (ml/24 h) & $10.41 \pm 1.20$ & $14.21 \pm 0.48^{\star}$ & $14.01 \pm 0.31^{\star}$ \\
\hline Plasma creatinine (mg/dl) & $0.58 \pm 0.01$ & $0.58 \pm 0.01$ & $0.57 \pm 0.02$ \\
\hline Plasma-Na+ $(\mathrm{mmol} / \mathrm{l})$ & $126.5 \pm 1.38$ & $126.12 \pm 1.73$ & $125.47 \pm 2.31$ \\
\hline Plasma-K+ $(\mathrm{mmol} / \mathrm{l})$ & $3.68 \pm 0.06$ & $3.65 \pm 0.07$ & $3.67 \pm 0.14$ \\
\hline Plasma-Cl- (mmol/l) & $113.74 \pm 1.97$ & $115.04 \pm 0.84$ & $111.84 \pm 1.55$ \\
\hline Urinary creatinine (mg/24 h) & $7.18 \pm 0.43$ & $8.07 \pm 0.15$ & $7.80 \pm 0.19$ \\
\hline Urinary $\mathrm{Na}^{+}(\mathrm{mmol} / 24 \mathrm{~h})$ & $1.03 \pm 0.03$ & $4.58 \pm 0.18^{\star \star}$ & $4.41 \pm 0.27^{\star \star}$ \\
\hline Urinary $\mathrm{K}^{+}$(mmol/24 h) & $3.43 \pm 0.18$ & $3.50 \pm 0.09$ & $3.46 \pm 0.12$ \\
\hline Urinary $\mathrm{Cl}^{-}$(mmol/24 h) & $1.72 \pm 0.10$ & $3.31 \pm 0.05^{\star \star}$ & $3.27 \pm 0.08^{\star \star}$ \\
\hline $\begin{array}{l}\text { Plasma osmolarity } \\
\left(\mathrm{mosn} / \mathrm{kg} \cdot \mathrm{H}_{2} \mathrm{O}\right)\end{array}$ & $312 \pm 2.06$ & $313 \pm 0.94$ & $312 \pm 1.27$ \\
\hline $\begin{array}{l}\text { Urine osmolarity } \\
\left(\mathrm{mosn} / \mathrm{kg} \cdot \mathrm{H}_{2} \mathrm{O}\right)\end{array}$ & \multicolumn{3}{|c|}{$1,340.4 \pm 34.601,407.00 \pm 45.521,379.50 \pm 49.75$} \\
\hline
\end{tabular}

Data represent the means \pm SEM. ${ }^{*} p<0.05,{ }^{* *} p<0.01$ vs. CTR. CTR, control.

bovine serum, and $1 \%$ penicillin-streptomycin. Cells were seeded on 6 well plates. After $24 \mathrm{~h}$, the cells were starved in media containing $0.5 \%$ FBS for $24 \mathrm{~h}$. Then the cells were treated with $10 \mathrm{mM}$ Pi for another $24 \mathrm{~h}$. To evaluate the effects of PRR on the levels of FGF23, PRO20 was given at $10 \mathrm{nM}$. To further verify the involvement of PRR, PRR was silenced by transfecting the cells with siRNA against PRR. Scrambled siRNA served as a control. SiRNA for mouse PRR and control siRNA were purchased from Ruibo Biotech (Guangzhou, China). After the treatment, the medium was collected and assayed for sPRR or FGF23 assays (EK5626, SAB, United States).

\section{Statistical Analysis}

Data is expressed as mean \pm standard error (SEM). All data points were included for analyses. Samples sizes were determined based on similar previous studies. Statistical analysis for animal and cell cultures experiments was performed by means of one-way analysis of variance (ANOVA) for multiple-group comparison or Student's $t$-test for two-group comparison. A $p$ value below 0.05 was considered statistically significant.

\section{RESULTS}

\section{Activation of (Pro)renin Receptor and Other Renin-Angiotensin System Components by High Pi Intake}

To test whether HP activated the RAS, we determined the levels of RAS components in urine and plasma from rats on normal $\mathrm{Pi}$ (NP) or HP intake using ELISA. The results showed that the levels angiotensinogen (AGT), renin, sPRR in urine and plasma from the HP group were significantly increased as compared with NP controls (Figure 1). By qRT-PCR, renal cortical mRNA expression of angiotensin-converting enzyme (ACE), AGT, renin, PRR were all increased in the HP group as compared with NP controls (Figure 2A). These results have been validated by Western blotting analysis. Of note, this analysis detected 
A

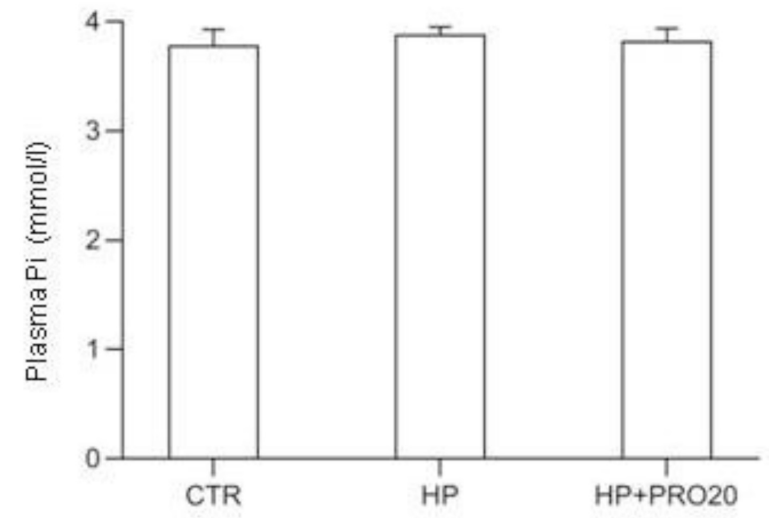

C

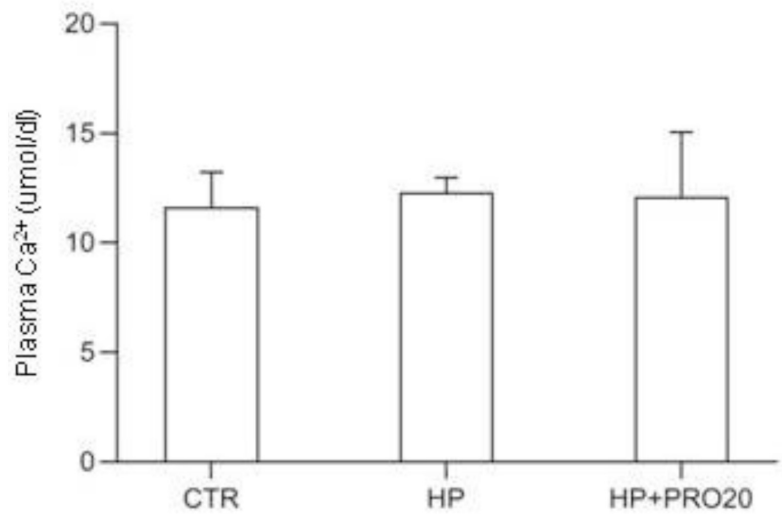

B

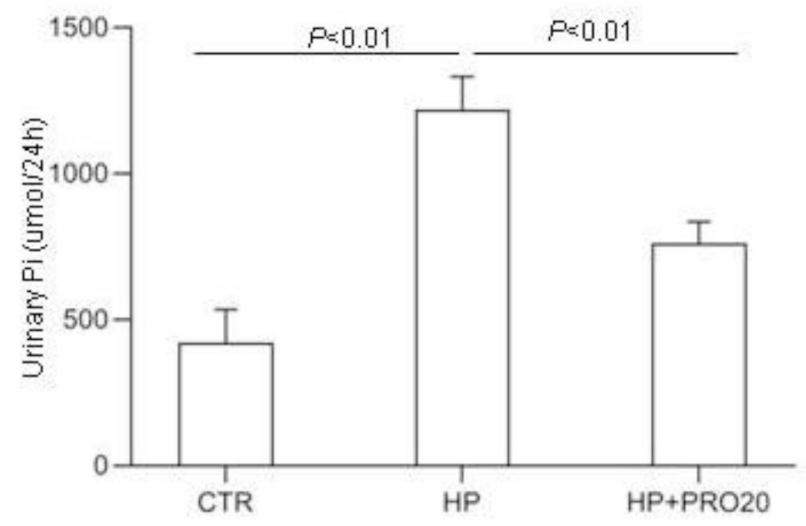

D

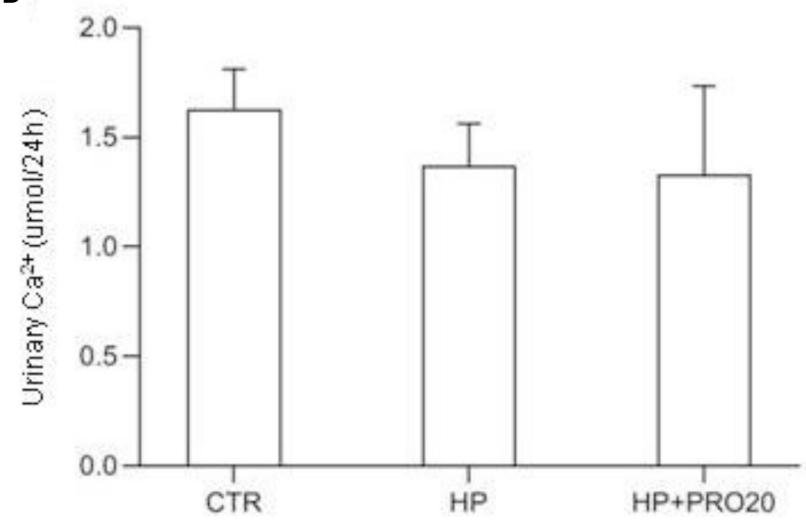

FIGURE 3 | Serum and urine biochemical parameters in NP, HP and HP + PRO20 rats. (A) Plasma Pi concentration; (B) 24-h urinary Pi excretion; (C) plasma Ca ${ }^{2+}$ concentration; (D) 24-h urinary $\mathrm{Ca}^{2+}$ excretion. $N=5$ per group. Data are Mean $\pm \mathrm{SEM}$.

increases in the protein abundances of both PRR and sPRR in the kidney of HP rats (Figure 2B). By immunohistochemistry, PRR protein expression was elevated in the collecting duct by $\mathrm{HP}$ treatment (Figure 2C), a pattern consistent with intercalated cell labeling as reported previously (Wang et al., 2016).

\section{Effect of PRO20 on Phosphaturic Response to High Pi Intake}

SD rats drank tap water, HP fluid alone or in combination with PRO20 treatment. Basic physiological data is shown in Table 1. Fluid intake was less but urine output was higher in HP rats as compared with vehicle control. This was paralleled with increased 24-h urinary excretion of $\mathrm{Na}^{+}, \mathrm{K}^{+}$, and $\mathrm{Cl}^{-}$induced by $\mathrm{HP}$ treatment. However, plasma creatinine and osmolality remained unchanged. None of these parameters were affected by PRO20.

To address the functional role of PRR in Pi homeostasis, we examined the effect of PRO20 on phosphaturic response to HP intake. HP intake induced a significant increase in urinary $\mathrm{Pi}$ excretion within $24 \mathrm{~h}$ and this increase was blunted by PRO20 treatment (Figure 3B). In parallel, HP intake elevated circulating FGF23 and PTH, both of which were nearly normalized by PRO20 treatment (Figures 4A,B). Despite reduced urinary Pi excretion, PRO20 treatment in HP rats did not affect plasma
Pi concentration (Figure $3 \mathbf{A}$ ). In a sharp contrast, plasma $\mathrm{Ca}^{2+}$ concentration (Figure 3C), urinary $\mathrm{Ca}^{2+}$ excretion (Figure 3D), or plasma $1,25(\mathrm{OH})_{2} \mathrm{D}_{3}$ (Figure $4 \mathrm{C}$ ) were unaffected by $\mathrm{HP}$ intake or PRO20 treatment.

In a separate experiment, we examined the effect of PRO20 on several key parameters of Pi homeostasis in 7-wk-old male $\mathrm{SD}$ rats under basal condition ( $n=5$ per group). The data showed that PRO20 had no effect on urinary Pi excretion (PRO20 $429.2 \pm 16.8$ vs. CTR $432.4 \pm 17.8 \mu \mathrm{mol} / 24 \mathrm{~h}, p>0.05)$, plasma $\mathrm{Pi}$ concentration (PRO20 $2.89 \pm 0.06$ vs. CTR $2.90 \pm 0.08$, $\mathrm{mmol} / \mathrm{L}, p>0.05$ ), plasma FGF-23 (PRO20 $374.3 \pm 15.4$ vs. CTR $381.3 \pm 10.2 \mathrm{pg} / \mathrm{ml}, p>0.05$ ), or urine volume (PRO20 $9.75 \pm 0.42$ vs. CTR, $10.45 \pm 0.85 \mathrm{ml}, p>0.05)$.

Downregulation of renal expression of sodium-phosphate cotransporters is a key determinant of phosphaturic response during HP intake (Murer et al., 1999; Hernando et al., 2001; Giral et al., 2009; Bourgeois et al., 2013; Forster et al., 2013; Zhuo et al., 2020). Therefore, we determined renal expression of Npt2a and Npt2c by both qRT-PCR and Western blotting analysis. In response to $\mathrm{HP}$ intake, renal cortical mRNA expression of $\mathrm{Npt} 2 \mathrm{a}$ was significantly decreased, which was blunted by PRO20 treatment (Figure 5A). In contrast, the mRNA expression of $\mathrm{Npt} 2 \mathrm{c}$ showed no significant changes in the three 

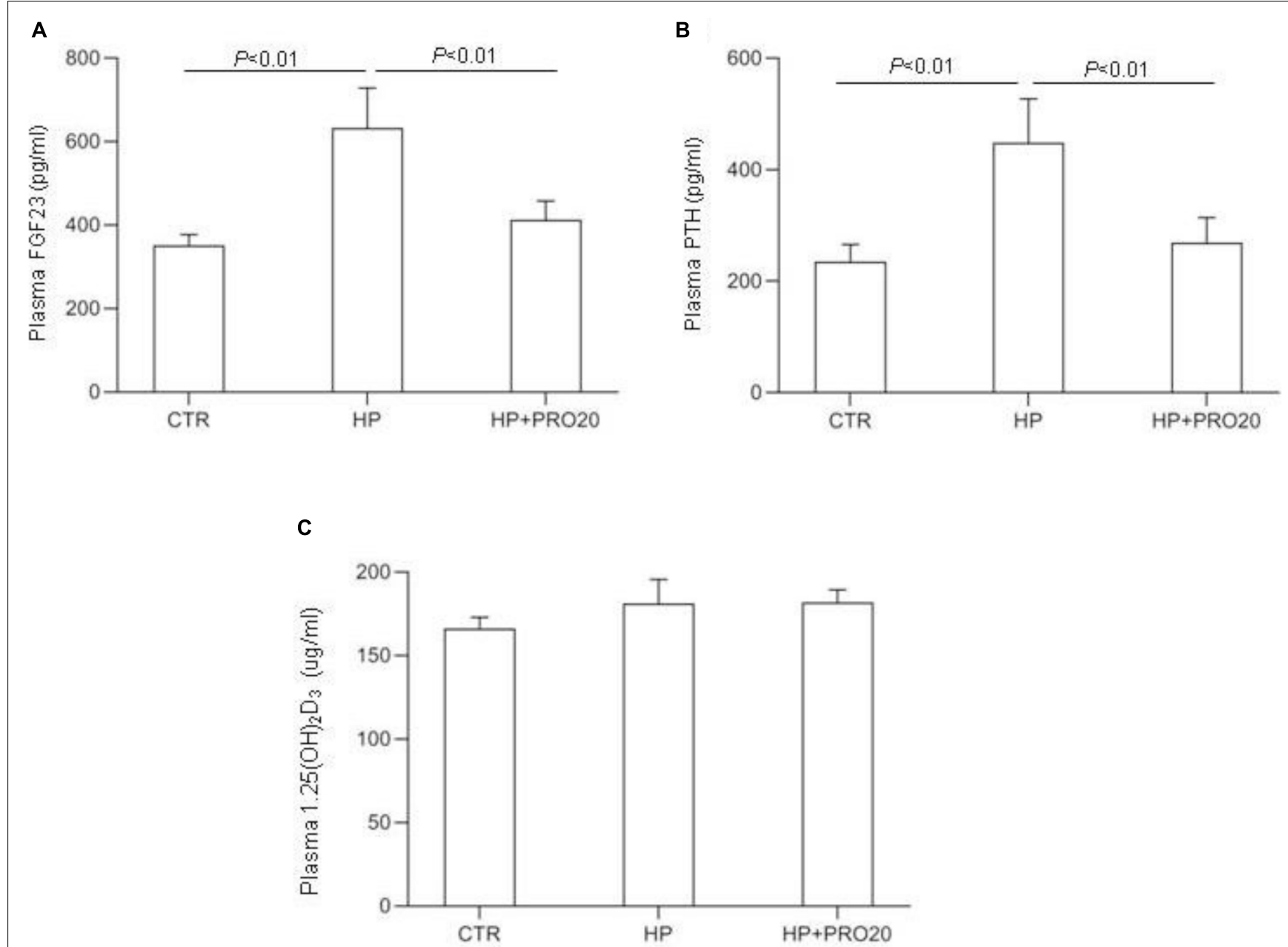

FIGURE 4 | Levels of plasma FGF23 (A), plasma PTH (B), and plasma 1,25(OH) $2 \mathrm{D}_{3}$ (C) were measured in CTR, HP, and HP + PRO20 rats. FGF23, fibroblast growth factor 23; PTH, parathyroid hormone; $N=5$ per group. Data are Mean \pm SEM.

groups (Figure 5A). Meanwhile, we examined the abundance of sodium-phosphate cotransporters in the kidney BBM by Western blotting analysis. The protein abundance of $\mathrm{Npt} 2 \mathrm{a}$ in BBM was downregulated by HP intake as compared with the NP control and this downregulation was prevented by PRO20 (Figure 5B). In contrast, no change was observed in protein abundance of $\mathrm{Npt} 2 \mathrm{C}$ in BBM (Figure 5B).

\section{Effect of (Pro)renin Receptor on FGF23 Production in Cultured MC3T3-E1 Cells}

The observation of suppressed circulating FGF23 concentration by PRO20 treatment during HP intake prompted us to speculate that the bone might be a potential site of PRR regulation of FGF23 release. To address this possibility, we conducted in vitro experiments using MC3T3-E1 cells, a mouse osteoblast cell line. The cells were exposed to normal or high $\mathrm{Pi}(10 \mathrm{mM} \mathrm{Pi})$ for $24 \mathrm{~h}$ followed by examination of expression of FGF23 as well as PRR. qRT-PCR results showed that the expression of PRR and FGF23 mRNA was both significantly increased by
HP treatment (Figure 6A). Consistent with this result, Western blotting analysis demonstrated significant elevations of protein abundance of full-length PRR (fPRR) and sPRR (Figure 6B). ELISA results showed that the concentrations of sPRR and FGF23 in the medium were significantly increased by HP treatment (Figures 6C,D).

Next, we examined the functional role of PRR in regulation of the production of FGF23 in the MC3T3-E1 cells by using PRO20. The cells were pretreated for $1 \mathrm{~h}$ with $10 \mu \mathrm{M}$ PRO20 and then treated with $10 \mathrm{mM} \mathrm{Pi}$ for $24 \mathrm{~h}$. By qRT-PCR, HP treatment increased the expression of FGF23 mRNA, and this increase was blunted by PRO20 (Figure 7A). This result was subsequently validated at protein level by ELISA (Figure 7B).

To further verify the above-mentioned results obtained with the pharmacological approach, we conducted independent experiments using siRNA approach to knockdown PRR. The efficacy of the gene knockdown was confirmed by qRT-PCR and Western blotting analysis (Figures 8A,B). PRR knockdown significantly blocked HP-induced FGF23 expression as assessed by qRT-PCR (Figure 8C) and ELISA (Figure 8D). 

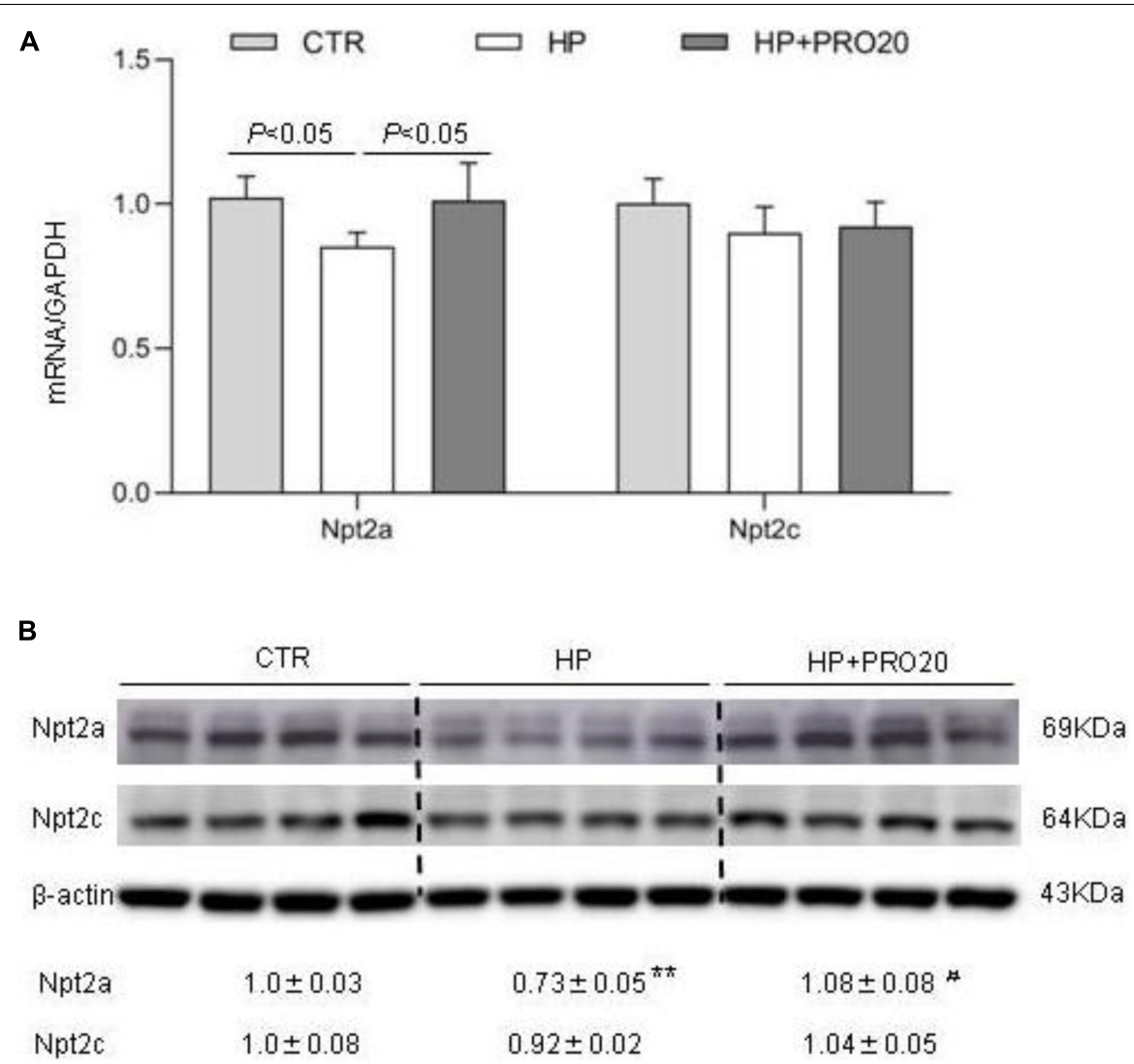

FIGURE 5 | Analysis of renal expression of Pi transporters in NP, HP and HP + PRO20 rats. (A) qRT-PCR analysis of renal mRNA expression of Npt2a and Npt2c. GAPDH was used as internal reference. (B) Immunoblotting analysis of Npt2a, and Npt2c protein expression. Brush border membrane was isolated from the kidney of all groups. The values indicate the corresponding densitometry analysis. $\beta$-actin was used as an internal reference. $N=5$ per group. Data are Mean \pm SEM. ${ }^{\star *} p<0.01$ vs. CTR, ${ }^{\#} p<0.05$ vs. HP.

\section{DISCUSSION}

PPR is a multi-functional protein critically involved in renal handling of $\mathrm{Na}^{+}, \mathrm{K}^{+}$and water through RAS-dependent or independent mechanisms (Lu et al., 2016a,b; Quadri and Siragy, 2016; Peng et al., 2017; Prieto et al., 2017; Xu et al., 2017; Ramkumar et al., 2018; Fu et al., 2019). The present study explored phosphaturic role of PRR during 24-h Pi loading. Following HP intake, the levels of circulating sPRR along with renal expression of PRR and other components of the RAS were all elevated in parallel with increased plasma FGF23 and PTH. PRR antagonism with PRO20 effectively suppressed HP-induced FGF23 and PTH levels and urinary Pi excretion albeit with unchanged plasma Pi concentration. Cell culture experiments offered a cellular mechanism of PRR regulation of FGF23 expression in an osteoblast cell line.

In response to $\mathrm{HP}$ intake, the levels of $\mathrm{PRR} / \mathrm{sPRR}$ were elevated as evidenced by increased circulating sPRR, the cleavage product of PRR, and renal expression of PRR. The source of sPRR under HP intake remains obscure. Immunostaining mapped HP-induced PRR expression in the collecting duct (CD) with a pattern of labeling in intercalated cells (ICs) as previously reported (Wang et al., 2016). It is intriguing that the CD may serve as a potential site for the generation of sPRR during HP intake although other organs such as bone or parathyroid gland may also be involved. ICs were initially thought to primarily regulate acid-base metabolism. However, emerging evidence suggests novel sensing function of ICs during urinary tract infection and acute kidney injury (Miao and Abraham, 2014; Azroyan et al., 2015; Battistone et al., 2020). More recent evidence suggests a paracrine mechanism whereby mediators such as SPRR or prostaglandins are produced by ICs and act in the neighboring principal cells of the CD to regulate $\mathrm{Na}^{+}$and water reabsorption in the distal nephron (Lu et al., 2016a,b; Xu et al., 2020). Our results indicate a possibility that IC PRR may be involved in regulation of $\mathrm{Pi}$ homeostasis by releasing $\mathrm{SPRR}$ that may target other organs to control production of phosphaturic hormones such as FGF23. The involvement of IC-derived sPRR in renal handling of Pi should be tested by future investigation.

Although PRR was initially identified as a specific receptor for prorenin and renin, its relationship with RAS has been debated (Binger and Muller, 2013). Recently, abundant evidence from our group strongly supports PRR as an important regulator of intrarenal RAS during water deprivation (Wang et al., 2016), angiotensin II-induced hypertension (Wang et al., 2014, 2017) and chronic kidney injury (Fang et al., 2018), favoring 

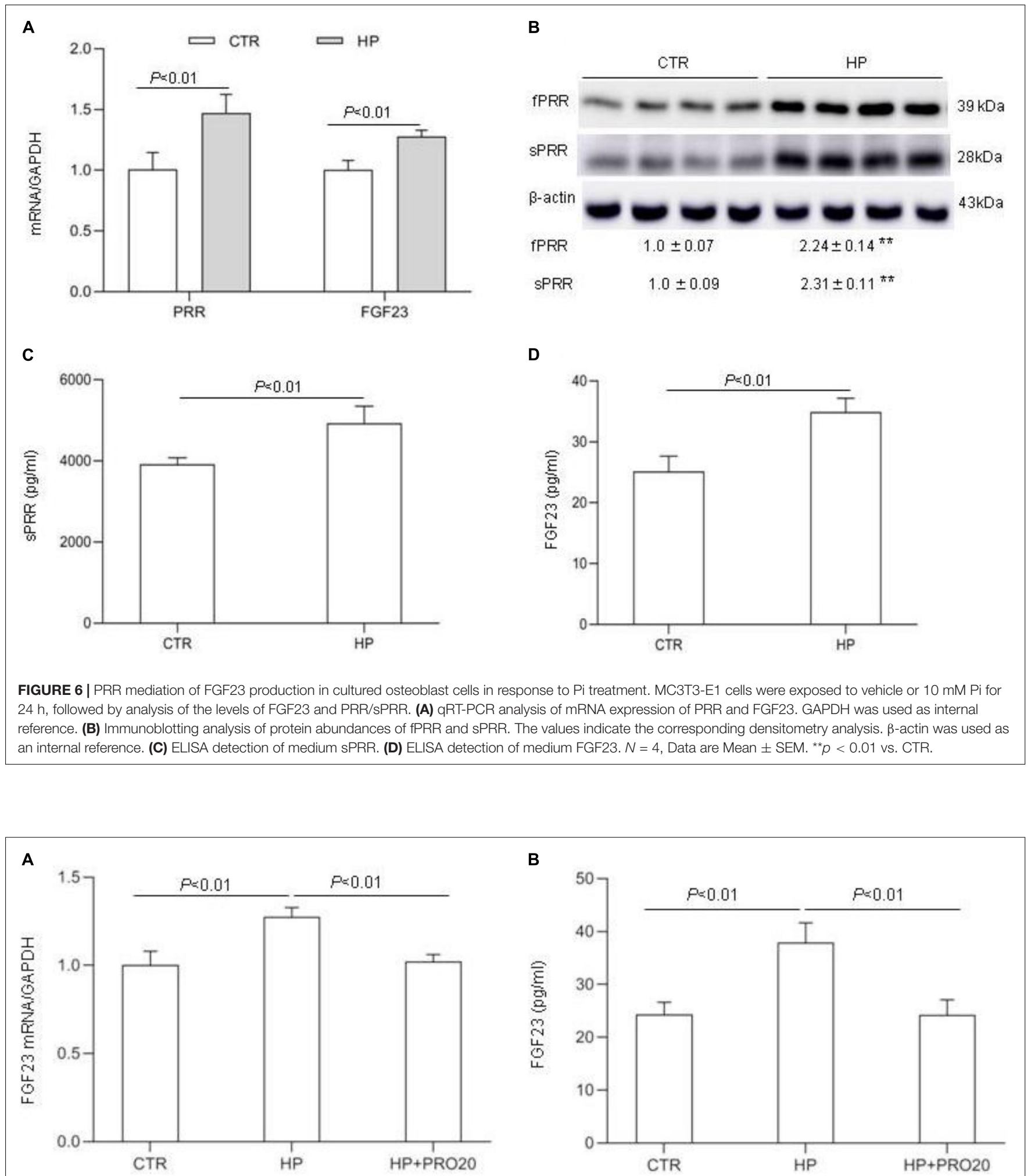

FIGURE 7 | Effects of PRO20 on the expression of FGF23 in MC3T3-E1 cells. The MC3T3-E1 cells were pretreated with PRO20 (10 $\mu$ M) for $1 \mathrm{~h}$, then treated with Pi $(10 \mathrm{mM})$ for $24 \mathrm{~h}$. (A) qRT-PCR analysis of mRNA expression of FGF23. GAPDH was used as internal reference. (B) ELISA detection of medium FGF23. $N=4$, Data are Mean \pm SEM. 


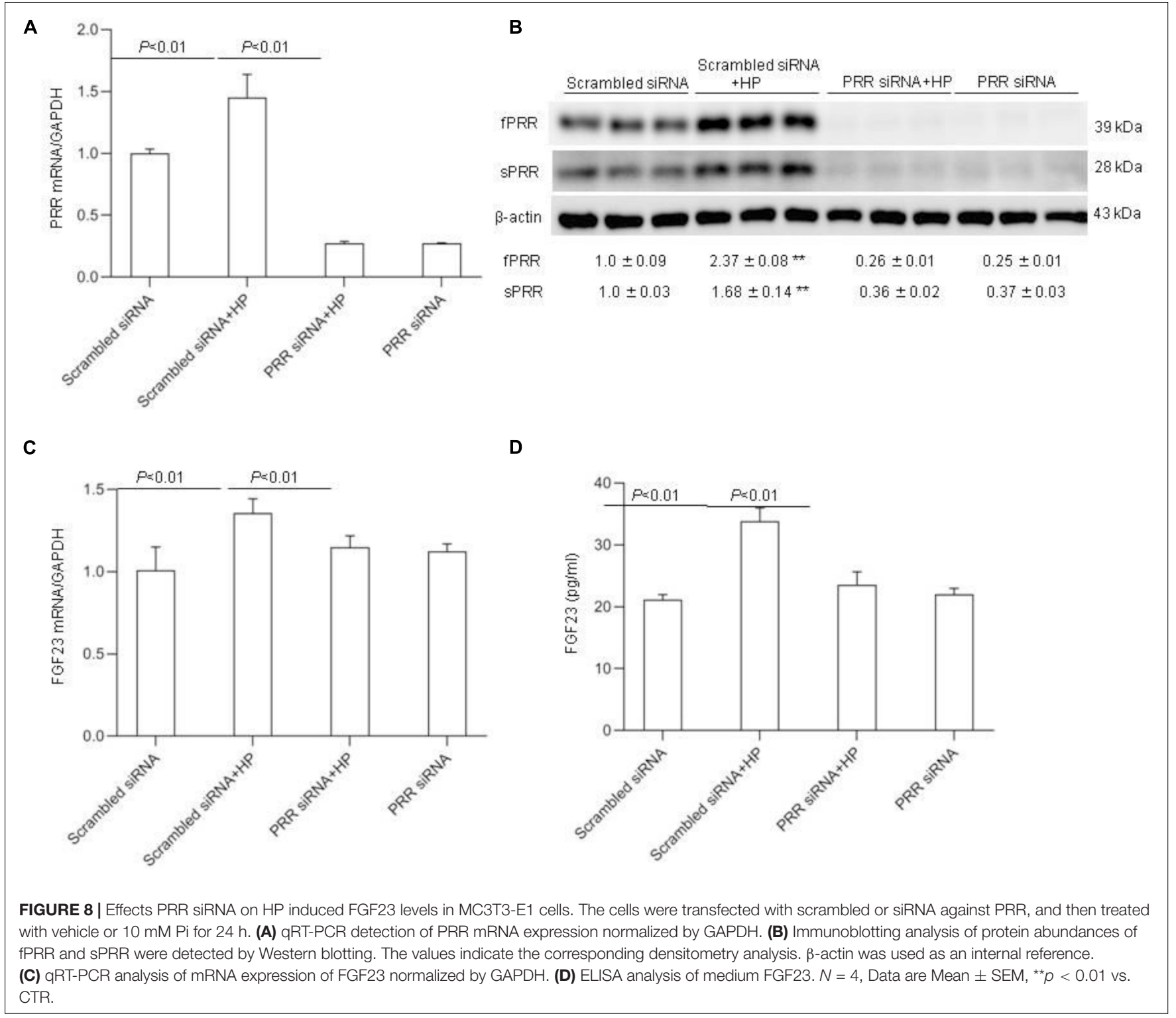

PRR as integrative member of the RAS. Along this line, the present study offered new evidence of activation of the RAS during HP intake. In this regard, HP treatment induced plasma and urinary excretion and renal expression of AGT and renin in parallel with elevated levels of PRR/sPRR. Future studies are needed to determine dependence of the canonical RAS components on PRR and its functional contribution to Pi homeostasis.

We employed a pharmacological approach to provide functional evidence for a novel role of PRR in mediating phosphaturic response to HP intake in rats. PRO20 has been extensively characterized as a highly specific and effective inhibitor of PRR owing to its peptide decoy activity (Danser, 2015; Li et al., 2015). Administration of PRO20 was highly effective in attenuating HP-induced urinary $\mathrm{Pi}$ excretion and phosphaturic hormones such as FGF23 and PTH. These hormones primarily target the kidney to downregulate abundance of $\mathrm{Npt} 2 \mathrm{a}$ in the brush border of proximal tubules. Indeed, HP-induced downregulation of Npt2a was prevented by PRO20 treatment. The result support phosphaturic role of PRR during $\mathrm{Pi}$ treatment. Of note, despite impaired phosphaturic response, PRO20 didn't elevate plasma Pi concentration during HP treatment. This might be due to the relatively short duration of HP treatment. Under this condition, effective compensatory mechanism might be activated and able to maintain normal level of plasma $\mathrm{Pi}$ concentration.

Osteoblast cells are a known source of FGF23 production during HP intake (Liu et al., 2003; Ferrari et al., 2005; Perwad et al., 2005; Lindberg et al., 2015; Goltzman et al., 2018). Considering the observation that PRO20 effectively suppressed HP-induced circulating level of FGF23, we hypothesized that 


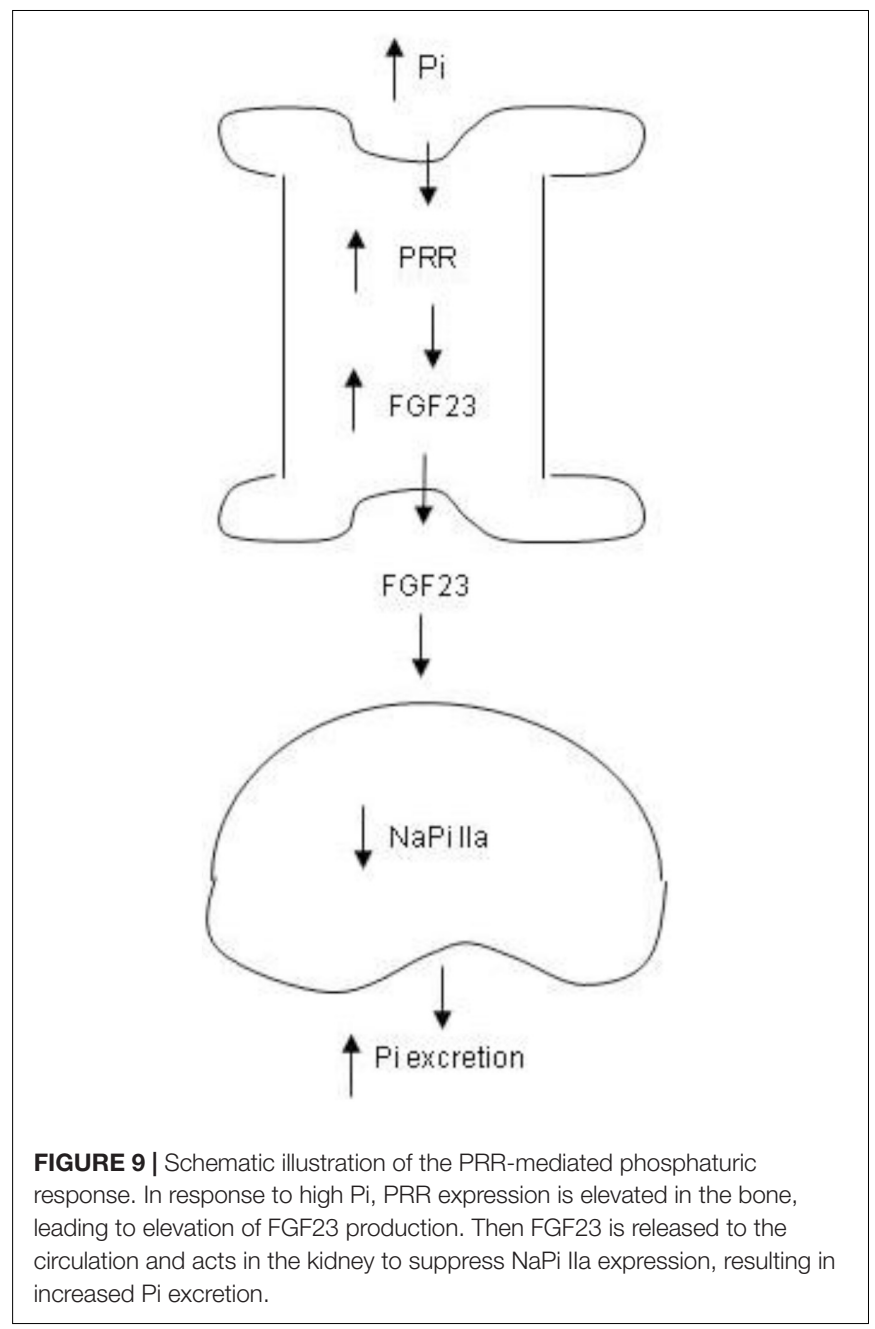

FGF23 production might be under the direct control of PRR in cultured osteoblast cells. Using a cell culture model of osteoblast cells, we obtained compelling evidence that HP-induced FGF23 mRNA expression and release were blunted by PRO20 and siRNA against PRR. We provided further evidence that PRR expression was stimulated by HP treatment. An issue may arise that the relative importance of PRR in osteoblast cells vs. the kidney for the control of FGF23 production remains unclear and should warrant future investigation.

Besides FGF23, PTH is another important regulator of $\mathrm{Pi}$ metabolism (Graciolli et al., 2009; Lombardi et al., 2020). In the present study, we were able to show an inhibitory effect of PRO20 on HP-induced plasma PTH level, indicating a potential role of PRR in regulation of the release of PTH, presumably from parathyroid gland. There is no information about expression and function of PRR in this organ in the context of PTH regulation. We would like to acknowledge this major limitation of the present study.

We would also like to acknowledge the limitation of the HP protocol used in the present study although this protocol has been validated by a previous study (Ide et al., 2016). The HP fluid contains high $\mathrm{NaCl}$ which may confoundingly influence Pi transport in the kidney through modulation of status of $\mathrm{NaPi}$ transporter. This possibility is suggested by the previous observation that subcellular distribution of $\mathrm{NaPi}$ 2 was altered following high salt diet (Yang et al., 2008), but with unchanged total abundance of this transporter. In contrast, as shown by the present study, the total abundance of NaPi-2 was downregulated by $24-\mathrm{h} \mathrm{HP}$ intake. This result seems to support a primary role of $\mathrm{NaPi}-2$ in regulating homeostasis of $\mathrm{Pi}$, probably not $\mathrm{Na}^{+}$. Indeed, besides $\mathrm{NaPi}$ $2, \mathrm{Na}^{+}$transport occurs via numerous other $\mathrm{Na}^{+}$transporters and channels in various nephron segments. Additionally, it seems hard to explain why HP intake reduced fluid intake that was contradictorily associated with increased urine output and urinary $\mathrm{Na}^{+}$excretion. Fortunately, we found no sign of severe dehydration as evidenced by unchanged plasma osmolality. This might be due to the short duration of the experiment and fluid balance can be maintained by activation of compensatory mechanisms.

In conclusion, we for the first time identified PRR as a novel mediator of phosphaturic response to HP intake. The phosphaturic action of PRR seemed to be mediated by stimulation of production of FGF23 as well as PTH (Figure 9). In vitro evidence from cultured osteoblast cells demonstrated that PRR directly mediated HP-induced FGF23 release. Overall, the present study has uncovered a previously undescribed PRR/FGF23 axis in regulation of Pi homeostasis.

\section{DATA AVAILABILITY STATEMENT}

The raw data supporting the conclusions of this article will be made available by the authors, without undue reservation.

\section{ETHICS STATEMENT}

The animal study was reviewed and approved by the Institutional Animal Care and Use Committee, Sun Yat-sen University.

\section{AUTHOR CONTRIBUTIONS}

TY and AL designed the research and wrote the manuscript. AL, JS, SM, MP, and JH performed the experiments. AL analyzed the data. AL, CL, WW, and TY edited and revised manuscript. TY approved final version of manuscript. All authors approved the final version of the manuscript.

\section{FUNDING}

This work was supported by the National Natural Science Foundation of China (Grant No. 81630013). TY was Senior Research Career Scientist in Department of Veterans Affairs. 


\section{REFERENCES}

Antoniucci, D. M., Yamashita, T., and Portale, A. A. (2006). Dietary phosphorus regulates serum fibroblast growth factor- 23 concentrations in healthy men. J. Clin. Endocrinol. Metab. 8, 3144-3149. doi: 10.1210/jc.2006-0021

Azroyan, A., Cortez-Retamozo, V., Bouley, R., Liberman, R., Ruan, Y. C., Kiselev, E., et al. (2015). Renal intercalated cells sense and mediate inflammation via the P2Y14 receptor. PLoS One 3:e0121419. doi: 10.1371/journal.pone.0121419

Battistone, M. A., Mendelsohn, A. C., Spallanzani, R. G., Allegretti, A. S., Liberman, R. N., Sesma, J., et al. (2020). Proinflammatory P2Y14 receptor inhibition protects against ischemic acute kidney injury in mice. J. Clin. Invest. 7, 37343749. doi: 10.1172/JCI134791

Beck, L., Karaplis, A. C., Amizuka, N., Hewson, A. S., Ozawa, H., and Tenenhouse, H. S. (1998). Targeted inactivation of Npt2 in mice leads to severe renal phosphate wasting, hypercalciuria, and skeletal abnormalities. Proc. Natl. Acad. Sci. U.S.A. 9, 5372-5377. doi: 10.1073/pnas.95.9.5372

Biber, J., and Murer, H. (1994). A molecular view of renal Na-dependent phosphate transport. Ren. Physiol. Biochem. 3-4, 212-215. doi: 10.1159/000173822

Binger, K. J., and Muller, D. N. (2013). Autophagy and the (Pro)renin receptor. Front. Endocrinol. 4:155. doi: 10.3389/fendo.2013.00155

Bourgeois, S., Capuano, P., Stange, G., Muhlemann, R., Murer, H., Biber, J., et al. (2013). The phosphate transporter NaPi-IIa determines the rapid renal adaptation to dietary phosphate intake in mouse irrespective of persistently high FGF23 levels. Pflugers Arch. 11, 1557-1572. doi: 10.1007/s00424-0131298-9

Burckle, C., and Bader, M. (2006). Prorenin and its ancient receptor. Hypertension 4, 549-551. doi: 10.1161/01.HYP.0000241132.48495.df

Busch, A., Waldegger, S., Herzer, T., Biber, J., Markovich, D., Hayes, G., et al. (1994). Electrophysiological analysis of $\mathrm{Na}+\mathrm{Pi}$ cotransport mediated by a transporter cloned from rat kidney and expressed in Xenopus oocytes. Proc. Natl. Acad. Sci. U.S.A. 17, 8205-8208. doi: 10.1073/pnas.91.17.8205

Danser, A. H. (2015). The Role of the (Pro)renin receptor in hypertensive disease. Am. J. Hypertens. 10, 1187-1196. doi: 10.1093/ajh/hpv045

Fang, H., Deng, M., Zhang, L., Lu, A., Su, J., Xu, C., et al. (2018). Role of (pro)renin receptor in albumin overload-induced nephropathy in rats. Am. J. Physiol. Renal. Physiol. 6, F1759-F1768. doi: 10.1152/ajprenal.00071.2018

Farrow, E. G., Davis, S. I., Summers, L. J., and White, K. E. (2009). Initial FGF23mediated signaling occurs in the distal convoluted tubule. J. Am. Soc. Nephrol. 5, 955-960. doi: 10.1681/ASN.2008070783

Ferrari, S. L., Bonjour, J. P., and Rizzoli, R. (2005). Fibroblast growth factor-23 relationship to dietary phosphate and renal phosphate handling in healthy young men. J. Clin. Endocrinol. Metab. 3, 1519-1524. doi: 10.1210/jc.2004-1039

Forster, I. C., Hernando, N., Biber, J., and Murer, H. (2013). Phosphate transporters of the SLC20 and SLC34 families. Mol. Aspects Med. 2-3, 386-395. doi: 10.1016/ j.mam.2012.07.007

Fu, Z., Hu, J., Zhou, L., Chen, Y., Deng, M., Liu, X., et al. (2019). (Pro)renin receptor contributes to pregnancy-induced sodium-water retention in rats via activation of intrarenal RAAS and alpha-ENaC. Am. J. Physiol. Renal Physiol. 3, F530-F538. doi: 10.1152/ajprenal.00411.2018

Gaasbeek, A., and Meinders, A. E. (2005). Hypophosphatemia: an update on its etiology and treatment. Am. J. Med. 10, 1094-1101. doi: 10.1016/j.amjmed. 2005.02.014

Gao, X., Zhang, S., Wang, D., Cheng, Y., Jiang, Y., and Liu, Y. (2020). (Pro)renin receptor contributes to hypoxia/reoxygenation-induced apoptosis and autophagy in myocardial cells via the beta-catenin signaling pathway. Physiol. Res. 3, 427-438. doi: 10.33549/physiolres.934210

Gattineni, J., Bates, C., Twombley, K., Dwarakanath, V., Robinson, M. L., Goetz, R., et al. (2009). FGF23 decreases renal NaPi-2a and NaPi-2c expression and induces hypophosphatemia in vivo predominantly via FGF receptor 1 . Am. J. Physiol. Renal Physiol. 2, F282-F291. doi: 10.1152/ajprenal.90742.2008

Giral, H., Caldas, Y., Sutherland, E., Wilson, P., Breusegem, S., Barry, N., et al. (2009). Regulation of rat intestinal Na-dependent phosphate transporters by dietary phosphate. Am. J. Physiol. Renal Physiol. 5, F1466-F1475. doi: 10.1152/ ajprenal.00279.2009

Goltzman, D., Mannstadt, M., and Marcocci, C. (2018). Physiology of the calciumparathyroid hormone-Vitamin D axis. Front. Horm. Res. 50, 1-13. doi: 10.1159/ 000486060
Gonzalez, A. A., and Prieto, M. C. (2015). Roles of collecting duct renin and (pro)renin receptor in hypertension: mini review. Ther. Adv. Cardiovasc. Dis. 4, 191-200. doi: 10.1177/1753944715574817

Graciolli, F. G., Neves, K. R., dos Reis, L. M., Graciolli, R. G., Noronha, I. L., Moyses, R. M., et al. (2009). Phosphorus overload and PTH induce aortic expression of Runx2 in experimental uraemia. Nephrol. Dial. Transplant. 5, 1416-1421. doi: 10.1093/ndt/gfn686

Guo, J., Song, L., Liu, M., Segawa, H., Miyamoto, K., Bringhurst, F. R., et al. (2013). Activation of a non-cAMP/PKA signaling pathway downstream of the $\mathrm{PTH} / \mathrm{PTHrP}$ receptor is essential for a sustained hypophosphatemic response to PTH infusion in male mice. Endocrinology 5, 1680-1689. doi: 10.1210/en. 2012-2240

Hernando, N., Karim-Jimenez, Z., Biber, J., and Murer, H. (2001). Molecular determinants for apical expression and regulatory membrane retrieval of the type IIa Na/Pi cotransporter. Kidney Int. 2, 431-435. doi: 10.1046/j.1523- 1755. 2001.060002431.x

Ide, N., Olauson, H., Sato, T., Densmore, M. J., Wang, H., Hanai, J. I., et al. (2016). In vivo evidence for a limited role of proximal tubular Klotho in renal phosphate handling. Kidney Int. 2, 348-362. doi: 10.1016/j.kint.2016.04.009

Katai, K., Miyamoto, K., Kishida, S., Segawa, H., Nii, T., Tanaka, H., et al. (1999). Regulation of intestinal $\mathrm{Na}+$-dependent phosphate co-transporters by a lowphosphate diet and 1,25-dihydroxyvitamin D3. Biochem. J. 343, 705-712. doi: 10.1042/bj3430705

Kouchi, M., Shibayama, Y., Ogawa, D., Miyake, K., Nishiyama, A., and Tamiya, T. (2017). (Pro)renin receptor is crucial for glioma development via the Wnt/betacatenin signaling pathway. J. Neurosurg. 4, 819-828. doi: 10.3171/2016.9. JNS16431

Larsson, T., Marsell, R., Schipani, E., Ohlsson, C., Ljunggren, O., Tenenhouse, H. S., et al. (2004). Transgenic mice expressing fibroblast growth factor 23 under the control of the alpha1(I) collagen promoter exhibit growth retardation, osteomalacia, and disturbed phosphate homeostasis. Endocrinology 7, 30873094. doi: 10.1210/en.2003-1768

Li, W., Sullivan, M. N., Zhang, S., Worker, C. J., Xiong, Z., Speth, R. C., et al. (2015). Intracerebroventricular infusion of the (Pro)renin receptor antagonist PRO20 attenuates deoxycorticosterone acetate-salt-induced hypertension. Hypertension 2, 352-361. doi: 10.1161/HYPERTENSIONAHA.114.04458

Li, Z., Zhou, L., Wang, Y., Miao, J., Hong, X., Hou, F. F., et al. (2017). (Pro)renin receptor is an amplifier of Wnt/beta-catenin signaling in kidney injury and fibrosis. J. Am. Soc. Nephrol. 8, 2393-2408. doi: 10.1681/ASN.2016070811

Lindberg, I., Pang, H. W., Stains, J. P., Clark, D., Yang, A. J., Bonewald, L., et al. (2015). FGF23 is endogenously phosphorylated in bone cells. J. Bone. Miner. Res. 3, 449-454. doi: 10.1002/jbmr.2354

Liu, S., Guo, R., Simpson, L. G., Xiao, Z. S., Burnham, C. E., and Quarles, L. D. (2003). Regulation of fibroblastic growth factor 23 expression but not degradation by PHEX. J. Biol. Chem. 39, 37419-37426. doi: 10.1074/jbc. M304544200

Liu, S., Zhou, J., Tang, W., Jiang, X., Rowe, D. W., and Quarles, L. D. (2006). Pathogenic role of Fgf23 in Hyp mice. Am. J. Physiol. Endocrinol. Metab. 1, E38-E49. doi: 10.1152/ajpendo.00008.2006

Lombardi, G., Ziemann, E., Banfi, G., and Corbetta, S. (2020). Physical activitydependent regulation of parathyroid hormone and calcium-phosphorous metabolism. Int. J. Mol. Sci. 15:5388. doi: 10.3390/ijms21155388

Lu, X., Wang, F., Liu, M., Yang, K. T., Nau, A., Kohan, D. E., et al. (2016a). Activation of $\mathrm{ENaC}$ in collecting duct cells by prorenin and its receptor PRR: involvement of Nox4-derived hydrogen peroxide. Am. J. Physiol. Renal Physiol. 11, F1243-F1250. doi: 10.1152/ajprenal.00492.2015

Lu, X., Wang, F., Xu, C., Soodvilai, S., Peng, K., Su, J., et al. (2016b). Soluble (pro)renin receptor via beta-catenin enhances urine concentration capability as a target of liver X receptor. Proc. Natl. Acad. Sci. U.S.A. 13, E1898-E1906. doi: $10.1073 /$ pnas. 1602397113

Miao, Y., and Abraham, S. N. (2014). Kidney alpha-intercalated cells and lipocalin 2: defending the urinary tract. J. Clin. Invest. 7, 2844-2846. doi: 10.1172/ JCI76630

Murer, H., Forster, I., and Biber, J. (2004). The sodium phosphate cotransporter family SLC34. Pflugers Arch. 5, 763-767. doi: 10.1007/s00424-003-1072-5

Murer, H., Forster, I., Hernando, N., Lambert, G., Traebert, M., and Biber, J. (1999). Posttranscriptional regulation of the proximal tubule NaPi-II transporter in 
response to PTH and dietary P(i). Am. J. Physiol. 5, F676-F684. doi: 10.1152/ ajprenal.1999.277.5.F676

Murer, H., Hernando, N., Forster, I., and Biber, J. (2000). Proximal tubular phosphate reabsorption: molecular mechanisms. Physiol. Rev. 4, 1373-1409. doi: 10.1152 /physrev.2000.80.4.1373

Murer, H., Hernando, N., Forster, I., and Biber, J. (2003). Regulation of Na/Pi transporter in the proximal tubule. Annu. Rev. Physiol. 65, 531-542. doi: 10.1146/annurev.physiol.65.042902.092424

Nakagawa, T., Suzuki-Nakagawa, C., Watanabe, A., Asami, E., Matsumoto, M., Nakano, M., et al. (2017). Site-1 protease is required for the generation of soluble (pro)renin receptor. J. Biochem. 4, 369-379. doi: 10.1093/jb/mvw080

Nguyen, G., Delarue, F., Burckle, C., Bouzhir, L., Giller, T., and Sraer, J. D. (2002). Pivotal role of the renin/prorenin receptor in angiotensin II production and cellular responses to renin. J. Clin. Invest. 11, 1417-1427. doi: 10.1172/ JCI0214276

Peng, K., Lu, X., Wang, F., Nau, A., Chen, R., Zhou, S. F., et al. (2017). Collecting duct (pro)renin receptor targets $\mathrm{ENaC}$ to mediate angiotensin II-induced hypertension. Am. J. Physiol. Renal Physiol. 2, F245-F253. doi: 10.1152/ ajprenal.00178.2016

Perwad, F., Azam, N., Zhang, M. Y., Yamashita, T., Tenenhouse, H. S., and Portale, A. A. (2005). Dietary and serum phosphorus regulate fibroblast growth factor 23 expression and 1,25-dihydroxyvitamin D metabolism in mice. Endocrinology 12, 5358-5364. doi: 10.1210/en.2005-0777

Perwad, F., Zhang, M. Y., Tenenhouse, H. S., and Portale, A. A. (2007). Fibroblast growth factor 23 impairs phosphorus and vitamin D metabolism in vivo and suppresses 25-hydroxyvitamin D-1alpha-hydroxylase expression in vitro. Am. J. Physiol. Renal Physiol. 5, F1577-F1583. doi: 10.1152/ajprenal.00463.2006

Pfister, M. F., Ruf, I., Stange, G., Ziegler, U., Lederer, E., Biber, J., et al. (1998). Parathyroid hormone leads to the lysosomal degradation of the renal type II Na/Pi cotransporter. Proc. Natl. Acad. Sci. U.S.A. 4, 1909-1914. doi: 10.1073/ pnas.95.4.1909

Prieto, M. C., Reverte, V., Mamenko, M., Kuczeriszka, M., Veiras, L. C., Rosales, C. B., et al. (2017). Collecting duct prorenin receptor knockout reduces renal function, increases sodium excretion, and mitigates renal responses in ANG II-induced hypertensive mice. Am. J. Physiol. Renal Physiol. 6, F1243-F1253. doi: 10.1152/ajprenal.00152.2017

Quadri, S., and Siragy, H. M. (2016). (Pro)renin receptor contributes to regulation of renal epithelial sodium channel. J. Hypertens. 3, 486-494. doi: 10.1097/HJH. 0000000000000825

Ramkumar, N., Stuart, D., Mironova, E., Abraham, N., Gao, Y., Wang, S., et al. (2018). Collecting duct principal, but not intercalated, cell prorenin receptor regulates renal sodium and water excretion. Am. J. Physiol. Renal Physiol. 3, F607-F617. doi: 10.1152/ajprenal.00122.2018

Saito, H., Maeda, A., Ohtomo, S., Hirata, M., Kusano, K., Kato, S., et al. (2005). Circulating FGF-23 is regulated by 1alpha,25-dihydroxyvitamin D3 and phosphorus in vivo. J. Biol. Chem. 4, 2543-2549. doi: 10.1074/jbc.M408903200

Shimada, T., Hasegawa, H., Yamazaki, Y., Muto, T., Hino, R., Takeuchi, Y., et al. (2004a). FGF-23 is a potent regulator of vitamin D metabolism and phosphate homeostasis. J. Bone Miner. Res. 3, 429-435. doi: 10.1359/JBMR.0301264

Shimada, T., Urakawa, I., Yamazaki, Y., Hasegawa, H., Hino, R., Yoneya, T., et al. (2004b). FGF-23 transgenic mice demonstrate hypophosphatemic rickets with reduced expression of sodium phosphate cotransporter type IIa. Biochem. Biophys. Res. Commun. 2, 409-414. doi: 10.1016/j.bbrc.2003.12.102

Shirazi-Beechey, S. P., Penny, J. I., Dyer, J., Wood, I. S., Tarpey, P. S., Scott, D., et al. (1996). Epithelial phosphate transport in ruminants, mechanisms and regulation. Kidney Int. 4, 992-996. doi: 10.1038/ki.1996.142
Urakawa, I., Yamazaki, Y., Shimada, T., Iijima, K., Hasegawa, H., Okawa, K., et al. (2006). Klotho converts canonical FGF receptor into a specific receptor for FGF23. Nature 7120, 770-774. doi: 10.1038/nature05315

Wang, F., Lu, X., Liu, M., Feng, Y., Zhou, S. F., and Yang, T. (2015). Renal medullary (pro)renin receptor contributes to angiotensin II-induced hypertension in rats via activation of the local renin-angiotensin system. BMC Med. 13:278. doi: 10.1186/s12916-015-0514-1

Wang, F., Lu, X., Peng, K., Du, Y., Zhou, S. F., Zhang, A., et al. (2014). Prostaglandin E-prostanoid4 receptor mediates angiotensin II-induced (pro)renin receptor expression in the rat renal medulla. Hypertension 2, 369-377. doi: 10.1161/ HYPERTENSIONAHA.114.03654

Wang, F., Lu, X., Peng, K., Fang, H., Zhou, L., Su, J., et al. (2016). Antidiuretic action of collecting duct (Pro)renin receptor downstream of vasopressin and PGE2 Receptor EP4. J. Am. Soc. Nephrol. 10, 3022-3034. doi: 10.1681/ASN. 2015050592

Wang, F., Sun, Y., Luo, R., Lu, X., Yang, B., and Yang, T. (2020). COX-2independent activation of renal (pro)renin receptor contributes to DOCA-salt hypertension in rats. Am. J. Physiol. Renal Physiol. 4, F647-F653. doi: 10.1152/ ajprenal.00112.2020

Wang, L., Zhu, Q., Lu, A., Liu, X., Zhang, L., Xu, C., et al. (2017). Sodium butyrate suppresses angiotensin II-induced hypertension by inhibition of renal (pro)renin receptor and intrarenal renin-angiotensin system. J. Hypertens. 9, 1899-1908. doi: 10.1097/HJH.0000000000001378

Xu, C., Lu, A., Wang, H., Fang, H., Zhou, L., Sun, P., et al. (2017). (Pro)Renin receptor regulates potassium homeostasis through a local mechanism. Am. J. Physiol. Renal Physiol. 3, F641-F656. doi: 10.1152/ajprenal.0004 3.2016

Xu, C., Wang, F., Chen, Y., Xie, S., Sng, D., Reversade, B., et al. (2020). ELABELA antagonizes intrarenal renin-angiotensin system to lower blood pressure and protects against renal injury. Am. J. Physiol. Renal Physiol. 5, F1122-F1135. doi: 10.1152/ajprenal.00606.2019

Yang, L. E., Sandberg, M. B., Can, A. D., Pihakaski-Maunsbach, K., and McDonough, A. A. (2008). Effects of dietary salt on renal $\mathrm{Na}+$ transporter subcellular distribution, abundance, and phosphorylation status. Am. J. Physiol. Renal Physiol. 4, F1003-F1016. doi: 10.1152/ajprenal.90235.2008

Zhuo, M. Q., Lv, W. H., Xu, Y. H., and Luo, Z. (2020). Isolation and characterization of three sodium-phosphate cotransporter genes and their transcriptional regulation in the grass carp Ctenopharyngodon idella. Int. J. Mol. Sci. 21:8228. doi: $10.3390 /$ ijms 21218228

Conflict of Interest: The authors declare that the research was conducted in the absence of any commercial or financial relationships that could be construed as a potential conflict of interest.

Publisher's Note: All claims expressed in this article are solely those of the authors and do not necessarily represent those of their affiliated organizations, or those of the publisher, the editors and the reviewers. Any product that may be evaluated in this article, or claim that may be made by its manufacturer, is not guaranteed or endorsed by the publisher.

Copyright (c) $2022 \mathrm{Lu}, \mathrm{Pu}, \mathrm{Mo}, \mathrm{Su}, \mathrm{Hu}, \mathrm{Li}$, Wang and Yang. This is an open-access article distributed under the terms of the Creative Commons Attribution License (CC BY). The use, distribution or reproduction in other forums is permitted, provided the original author(s) and the copyright owner(s) are credited and that the original publication in this journal is cited, in accordance with accepted academic practice. No use, distribution or reproduction is permitted which does not comply with these terms. 